\title{
O CAMPO DE TRABALHO: RELATOS ETNOGRÁFICOS
}

\author{
Vera Lúcia Maia Marques ${ }^{1}$
}

\section{Um caminhar}

\begin{abstract}
Concluir esta tese foi viajar por um longo caminho. Foi um viajar sozinha, por lugares desconhecidos, para compreender o caminhar dos "meus outros": os muçulmanos.

Sentimentos de dúvidas e de certezas ao mesmo tempo. Busca de conhecimento, vontade de entender de tudo um pouco para saber um mínimo da complexa arte do saber. Foi o desvendar de algo, que no início eu não sabia bem o que era, mas que sentia e quase podia tocar. Mas era como tocar no etéreo. Estava ali, mas eu não via, só sentia (Marques, 2009: 248).
\end{abstract}

A experiência, que passa de pessoa para pessoa, é para Walter Benjamin (1985) a principal fonte da narrativa. E a "viagem" é uma dessas fontes, pois quem viaja tem sempre algo a contar. Pode-se mesmo dizer que se viaja para se ter o que contar. Portanto, é esta "viagem" e experiência que deixo aos leitores num relato, na primeira pessoa, sobre a minha pesquisa de campo, uma etnografia, composta por dois roteiros. O primeiro roteiro foi no Brasil, para a minha pesquisa de mestrado, focado no processo de conversão de brasileiros, sem ascendência muçulmana e/ou árabe, origem essa predominante entre os muçulmanos que vivem no Brasil ${ }^{2}$. O segundo roteiro comparou as práticas religiosas dos convertidos ao Islã no Brasil e em Portugal. Foi, no primeiro caso, um viajar por um mundo sutil, na busca de entender os projetos individuais de conversão dos sujeitos, enquanto esses mesmos sujeitos buscavam no Islã a reorganização e reconfiguração de suas vidas. Portanto, como um "jogo de espelhos", uma "imagem de si refletida no outro que orienta e conduz o olhar em busca de significados" (Magnani, 1996: 21). A segunda viagem foi para Portugal, no país do "outro", numa "espécie de exílio deliberado" (Amorim, 2001 : 26). Foi um período curto mas muito intenso.

Para melhor contextualizar essa minha narrativa, descrevo um pouco mais sobre os dois campos pesquisados. No Brasil, a pesquisa foi realizada com muçulmanos em São Paulo e sua região metropolitana. A pesquisa evidenciou, através dos dados recolhidos em campo, que, na busca de reorganização de seus projetos de vida, os novos

\footnotetext{
${ }^{1}$ Universidade Federal de Minas Gerais, Brasil.

2 Ver em Marques (2000).
} 
muçulmanos brasileiros além de encontrarem no Islã uma reconfiguração de suas vidas, também encontraram um sentimento de igualdade, de justiça e uma outra experiência religiosa. Todavia, embora houvesse um sentimento de pertencimento religioso, os relatos apontavam para as dificuldades de acomodação nessa coletividade. Isso porque, como a maioria muçulmana que se encontra no Brasil resulta da imigração de libaneses, de sírios e de palestinos, os "convertidos" sentiam, como fonte de conflito, o que chamam de "arabismo", o que, segundo alguns, sobrepõe-se à "islamização". Vale ressaltar que atualmente é possível encontrar, entre os muçulmanos estabelecidos no país, imigrantes de outras origens - africanos, asiáticos, dentre outros -, mas ainda são os "árabes" a sua maioria. Um outro perfil tem se delineado, pelo crescimento do número de convertidos, inclusive de jovens negros que estabelecidos nas periferias das cidades brasileiras divulgam o Islã pelo rap e hip-hop.

As mulheres começaram a se destacar como protagonistas, à medida que as entrevistas foram sendo realizadas, embora os homens tenham contribuído, permitindo a ampliação do meu campo de visão. Os contatos foram feitos dentro das mesquitas, mas também foram feitos em outros locais (espaços públicos e privados). Entretanto, as entrevistas foram realizadas, na maioria das vezes, fora do âmbito religioso. O objetivo era, de fato, propiciar que se expressassem o mais abertamente, com a menor interferência possível do local. Portanto, a minha presença no campo de pesquisa fez-se com visitas frequentes às mesquitas e suas instituições, contatos nos finais de semana, em congressos islâmicos, em festas religiosas, em casamentos.

Partindo dos dados empíricos, que eu trouxe na bagagem da minha primeira viagem, e frente às controvérsias sobre a temática que envolve o Islã, como os constantes ataques terroristas, tanto nas zonas de conflito como fora delas e, sobretudo, o seu crescimento no mundo, julguei apropriada uma ampliação da pesquisa. Assim, escolhi Portugal.

Essa minha escolha se deu pelas relações históricas e culturais entre os dois países e pela diferença de procedência dos muçulmanos. Enquanto no Brasil a maioria muçulmana era constituída, como já dito, por imigrantes de procedência árabe, em Portugal o grupo era bem mais diversificado: Imigrantes indo-moçambicanos, guineenses, bangladeshianos, paquistaneses, marroquinos, dentre outros grupos menores, o que faz desse campo um interessante mosaico de práticas culturais e religiosas. Além disso, o meu interesse surgiu também pela presença do "catolicismo", 
como matriz cultural nos dois países, pela presença dos portugueses de origem moura e de escravos africanos muçulmanos trazidos pelos colonizadores portugueses e pelo interesse na ampliação e na intensificação dos diálogos acadêmicos entre Brasil e Portugal.

\title{
Uma viagem
}

\begin{abstract}
Eu tinha a certeza de que uma tese não poderia ser somente o sentir, precisava mais, teria que ser objetiva. Por isso, foi preciso uma conversão. Uma conversão de sentimentos em realidades, imaginação em conhecimento. Como o processo da conversão religiosa reúne um conjunto de fatores e de circunstâncias que leva o indivíduo a buscar e a conhecer uma outra dimensão do sagrado, a pesquisadora também trilhou seus caminhos na busca da dimensão desconhecida. Senti, compreendi e segui caminhando. Ouvi durante "meu trabalho de campo" que o convertido é um "ser só". E "só" também é quem tenta buscar, no sentimento do outro, o seu próprio sentimento, o entendimento que sequer entendem bem. Dentro desse "meu mundo particular" de investigação, quantas vezes me apanhei perguntando por que seguir adiante, diante dos empecilhos com os quais me deparei durante esta "minha viagem". Questionei. Mas, de fato, nunca consegui parar. Ao contrário, as dificuldades levaram-me adiante (Marques, 2009: 248-249).
\end{abstract}

$\mathrm{Na}$ minha segunda viagem, que originou a tese de doutorado, voltei aos mesmos sujeitos entrevistados no Brasil, com objetivo de detectar possíveis mudanças. Estabeleci-me, portanto, novamente no campo brasileiro e ampliei o foco analítico, não somente aos convertidos, mas também aos muçulmanos de uma forma mais ampla. Entretanto, será no campo português que farei a minha narrativa e contarei as minhas experiências, pois o "estar lá" (Geertz, 1989) obrigou-me a uma reflexão, tanto sobre a inserção da pesquisadora nesse campo de pesquisa complexo quanto da viajante em terras alheias, atravessado por diferenças culturais, em diferentes planos: nacionais, religiosas, geográficas, linguísticas.

Pois bem, no campo português, permaneci, a maior parte do tempo, em contato com os muçulmanos na Mesquita Central de Lisboa, onde a maioria se concentra, e também tive a oportunidade de visitar outras mesquitas no país. Foram seis meses, graças a uma "bolsa sanduíche" concedida pela CAPES-MEC (Coordenação de Aperfeiçoamento de Pessoal de Nível Superior - Ministério da Educação), em cooperação com a Universidade Nova de Lisboa, onde contei com a co-orientação da professora Dra. Susana Pereira Bastos, além, é claro, da professora Dra. Léa Freitas Perez, minha orientadora na UFMG. 
Numa retrospectiva, posso afirmar que as minhas primeiras impressões no campo podem se resumir a uma expressão: Tudo era inusitado! O que mais chamou a minha atenção foi o colorido das roupas das mulheres guineenses e a alegria com que elas cumprimentavam-se e cumprimentavam-me. Elas sobressaíam entre as outras muçulmanas de procedência indo-moçambicanas, mesmo porque as muçulmanas de procedência asiática não têm o hábito de ir à jummah (oração congregacional de sexta feira). Portanto, as guineenses eram a maioria na mesquita. Num primeiro momento, não consegui distinguir quem era asiático, africano, europeu. Mas também percebi, ao sair da mesquita, naquela sexta-feira, 22 de agosto de 2008, que os homens e as mulheres juntavam-se e conversavam muito descontraidamente. Eu estava fascinada!

Naquele dia, a mesquita estava lotada. Terminando a oração, resolvi procurar pelo imam (o líder religioso), pois queria apresentar-me, explicar sobre a minha pesquisa e pedir-lhe autorização para "estar lá", durante o período de seis meses, tempo que ficaria em Portugal. Tão rapidamente quanto me ouviu, falou sobre a comissão de apoio aos convertidos. Foi-me sugerido contatar o “maulana” responsável por essa comissão ${ }^{3}$. O contato pelo e-mail foi eficiente e, na semana seguinte, eu já participava de uma reunião promovida por ele. O tema dessa reunião era a importância do "Ramadã", um dos pilares do Islã, que começaria em um ou dois dias, dependendo da mudança da lua. Era um grupo formado por 12 pessoas, sendo a maioria de convertidos. Ao terminar a exposição do sheikh, tive a oportunidade de explicar o motivo da minha presença na mesquita e saber se poderia contar com a contribuição deles. Apenas duas pessoas se manifestaram: uma convertida, que pertencia à comissão dos convertidos, e um convertido, que era também um pesquisador. A partir daí, participei intensamente das atividades do Ramadã, de vários iftar (quebra do jejum), encontros, conferências, Eid al-Fitr (festa de encerramento do Ramadã), do Eid al-Adha (Festa do Sacrifício), das aulas de religião que seguiam às aulas de árabe todos os sábados na mesquita e, onde, por vezes, havia conferências com temas variados.

$\mathrm{Na}$ festa do Eid al-Fitr, a Mesquita Central estava tão lotada que as orações foram feitas em duas etapas. Os homens espalharam-se entre o salão principal, o jardim aberto, a parte de cima, reservada às mulheres, e um enorme espaço, normalmente utilizado para eventos, como no caso das conferências, e que serve de restaurante dos homens na quebra do jejum. Do lado de fora era um mar de sapatos. As mulheres ocuparam uma

\footnotetext{
${ }^{3}$ Maulana, é uma forma particularmente asiática de se referir ao sheikh.
} 
parte bem menor, mas não menos cheia. Era um dia de festa e as pessoas demoraram para se dispersar à saída da mesquita. Conversavam e fotografavam os familiares e os amigos, cristalizando aquele momento de alegria, de celebração e de comunhão.

Enfim, senti-me inserida no "meu campo" de pesquisa, que fez-se possível com a autorização do imam David Munir e pela ajuda do sheikh (maulana) Zabir, dirigente da “Comissão de Apoio Religioso aos Recém-Convertidos / Revertidos", já referido anteriormente e, claro, pelos muçulmanos que comecei a manter o meu contato. Mas, devo ressaltar que embora inserida, senti certa resistência por parte de alguns “convertidos portugueses". Com isso, aproveitei ao máximo os encontros no Ramadã ou aos sábados, as palestras, as festividades e as orações de sextas feiras para as minhas observações e conversas, ainda que informais. Por vezes, tive a oportunidade de estar por mais tempo junto aos interlocutores convertidos, inclusive em viagens longas, em congressos dentro e fora do país.

Observei, conversei, aprendi mais sobre as práticas religiosas e culturais, e tentei entender melhor os meus interlocutores. Entretanto, com o tempo, senti que alguns portugueses, com quem eu havia tido um contato mais estreito no começo, já não estavam muito disponíveis, as entrevistas ficavam cada vez mais difíceis de serem marcadas e realizadas (um pouco também pela dispersão após o Ramadã). Embora em nenhum momento eu tivesse sido maltratada, por parte de nenhum dos muçulmanos, convertidos ou "nascidos muçulmanos", comecei, no entanto, a sentir-me afastada, ou, pelo menos, não comunicada de alguns dos eventos entre os convertidos.

\section{Uma reflexão}

Passei a buscar respostas, embora algumas estivessem ao meu alcance e outras talvez nunca as alcance. E fui adiante. Entre os altos e baixos que o trajeto me impunha e entre momentos de desânimo e de euforia. Curiosamente, ouvi no "meu campo de investigação", de uma das minhas interlocutoras, que se dizia atéia antes de se converter ao Islã, que a conversão se deu por ela não ter encontrado, em suas buscas, um motivo para não acreditar em Deus. Assim, eu também não encontrei um forte estímulo para desistir. Estar em Portugal trouxe-me ainda outros sentimentos. Além de ser "o outro", fui "migrante", mesmo que temporário. Foram seis meses que não vi passar, que vivi intensamente a "minha investigação", que senti dificuldades, tanto dentro do "meu campo" quanto fora dele, mas que, por outro lado, foram recompensados com final desta tese. Precisava ganhar a confiança dos muçulmanos, dos imigrantes e dos portugueses. Consegui, enfim, a confiança de alguns, mas houve exceção. O mesmo "preconceito" que algumas vezes lhes era imposto, pela sociedade envolvente, também me envolveu (Marques, 2009: 249250). 
A partir dos anos 1990, a imigração para Portugal intensificou-se, devido ao crescimento do país e em consequência da sua integração à Comunidade Européia. Com isso, a emigração dos portugueses para os outros países europeus estabilizou-se e a imigração no país disparou. E é nessa imigração recente que os brasileiros estão incluídos. Em 2003, Portugal fez cerca de 30.000 legalizações de brasileiros no país. A partir da mesma época, os meios de comunicação portugueses noticiaram a "exploração de mulheres por redes de tráfico e prostituição nas cidades do interior do país" (Cunha, $2004: 536)$.

O caso das "mães de Bragança" ou das "meninas de Bragança", ocorrido nessa cidade em maio de 2003, ficou conhecido porque culminou num manifesto e abaixoassinado, que foram apresentados às autoridades pedindo providências contra as prostitutas brasileiras ou "alternadeiras", que estariam "a virar a cabeça dos maridos". Entre este e outros motivos, os brasileiros passaram a integrar a lista de imigrantes a sofrer discriminações.

Uma reportagem do Diário dos Açores ganhou a minha total atenção: "Senhorios recusam arrendar quartos a brasileiros e africanos". Isso porque foi exatamente o que havia ocorrido comigo. Assim que cheguei em Portugal, comecei a procurar um lugar para morar. No entanto, em várias ocasiões, ao saber de tratar-se de uma brasileira os senhorios ou corretores diziam que o imóvel já teria sido alugado, tal e qual descrevia a publicação:

\begin{abstract}
... a Lusa descobriu que quando o sotaque é português aqueles quartos estão livres. São cerca de três mil os brasileiros a estudar no ensino superior em Portugal. Os que não têm familiares ou amigos a viver no país atravessam sérias dificuldades para conseguir arrendar um quarto ou uma casa. As raparigas são associadas à prostituição e os rapazes à criminalidade. Há quem acuse os portugueses de "um racismo camuflado" (23.09.2008).
\end{abstract}

Outra matéria da Folha on line $e^{4}$ dizia: "Estudo da UE diz que 44\% dos brasileiros em Portugal já sofreram discriminação”. O estudo mostrava ainda que $74 \%$ dos brasileiros consideram alto o nível de discriminação e de racismo em Portugal.

A investigadora Isabel Ferin Cunha, ao desenvolver seu trabalho com imigrantes brasileiras em Portugal, levantou as seguintes questões:

\footnotetext{
${ }^{4}$ Folha on line de 23.04.2009. http://www1.folha.uol.com.br/folha/bbc/ult272u554954.shtml
} 
Haverá alguma relação entre as imagens da mulher na telenovela brasileira, a imigração brasileira e os contornos sociais que envolvem a sua aceitação e integração em Portugal? Em que medida há uma interrelação entre as imagens e as representações sensuais e sexualizadas veiculadas nas telenovelas e os subtis fenómenos de discriminação da mulher brasileira em Portugal? Em que medida essas representações e imagens fazem o sucesso das meninas brasileiras nas casas de alterne [casas de prostituição] e desestabilizam uma cidade? Como os meios de comunicação, imprensa e televisão, cobrem estes acontecimentos? (2004 : 535 grifos da autora).

Estas e outras questões por si só fizeram-me pensar sobre o meu campo de trabalho, o que antes era normal, ou seja, a rejeição de uma ou outra portuguesa, passou a ser mais um campo de reflexão.

Algumas hipóteses foram consideradas. O fato de ser brasileira, de uma certa maneira, pode ter contribuído para o afastamento ou para a não aproximação de alguns membros do grupo, assim como o não ser muçulmana, também teve algum peso na desmotivação da continuidade do contato, embora tenha sido favorável, num período inicial. Isso porque, alguns pesquisadores que conheceram o Islã e os muçulmanos, naquele contexto, se converteram. Porém, a minha insistência em colocar-me como uma pesquisadora, e não como uma possível convertida, de alguma forma, fechou portas. Não havia percebido que o fato de ser mulher pudesse também ter uma influência direta na minha aceitação entre os muçulmanos e o afastamento de alguns a posteriori. Talvez, o fato de ser mulher fosse até favorável, levando em conta que a maioria das pessoas que se convertem em Portugal é composta por mulheres.

Enfim, eu estava entre os muçulmanos, mas eu não era uma deles. Eu era uma pesquisadora. Eu era uma estranha. Eu era uma estrangeira. Nesse momento uma reflexão sobre essa minha inserção no "meu campo de pesquisa" foi necessária. Fiz uma retrospectiva dos momentos vividos. Não desisti e entendi que entre todas as experiências até então um fato teria passado desapercebido: Ser brasileira.

Lembrei que nos meus primeiros contatos com o grupo nem todas as convertidas quiseram uma maior aproximação. No momento entendi e achei normal a desconfiança. Entretanto, com o passar do tempo, soube que o fato de eu ser brasileira não agradava a todas. Achei engraçado, até que em um dado momento, resolvi entender melhor o que significava "ser brasileira". 


\title{
Enfim, a pesquisadora e sua etnografia
}

\begin{abstract}
Mesmo sem as dificuldades da língua, houve dificuldades em relação à cultura. "Nós" informais. "Eles" formais. "Nós" abertos ao diálogo. "Eles" querendo a sua privacidade. Um descuido tornaria tudo mais difícil. Além disso, eu estava "lá" num campo complexo do Islã. Engraçado, ouvi que eu estava ali como uma "fiscal". Sim, eu estava ali, aos olhos de alguns, como uma "fiscal", porque, certamente, eu não era uma deles. Eu era uma curiosa, que observava, mas, definitivamente, não era uma deles. Não posso negar que tive ajuda de muitos e que fui bem recepcionada, mas tive que me desdobrar para provar que o que eu queria era apenas compreender, saber. Tive também que ser "o dobro simpática", e "esforçar sempre, muito mais", tal e qual me disse uma interlocutora. E essa não foi uma tarefa nada fácil, ao contrário, foi árdua (Marques, 2009 : 250).
\end{abstract}

As diferenças definem o pesquisador e o pesquisado; diferenças essas que são o ponto de partida da pesquisa em que o "outro é posto como enigma" (Amorim, 2001 : 24). Esse outro, que pode ser o pesquisado ou o pesquisador, uma "viajante potencial", que se colocou num "grupo espacial particular", sem, entretanto, ser um "elemento próprio do grupo", uma estrangeira (Simmel, 183 : 182-183). Entretanto, essa relação entre o pesquisador-pesquisado, que ouve e é ouvido, participa e é participante, faz uma troca, um diálogo que faz com que ambos reflitam sobre si e sobre o outro, abrindo campo a novos questionamentos. Dos riscos que toda pesquisa, ou viagem que o pesquisador está sujeito, creio que tive êxito, pois tirei proveito de cada um dos percalços que tive durante a minha jornada. E é por isso, que concluo este texto com mais um extrato da minha reflexão, o meu "posfácio", onde coloquei corpo e alma e que dei vida a essa narrativa, desde o início.

Assim, essa etnografia foi uma viagem que, pela janela vê paisagens, recortadas pela moldura que limita a nossa visão. Realidades que se deixam ver, entre o belo e o exótico. São marcas e sentimentos que ficam gravados no nosso íntimo. Cheiros e sensações que ficam guardados como lembranças dos momentos em campo.

Meus dois roteiros de viagem foram marcados por dois instantes e locais distintos. O primeiro, marcado pelo stress de um tempo sem muito tempo. Um acúmulo de conhecimento e de estar "cá", onde ora eu viajava ao mundo sutil que buscava, ora caía na realidade de uma vida dos trabalhos frenéticos do dia a dia. Ao contrário dos meus interlocutores, a "minha viagem" sonhada era para eles a vida vivida. Entretanto, foram eles que permitiram com que eu sonhasse e buscasse, nas entrelinhas e nos seus cotidianos, o que eu precisava para viver essa grande viagem pessoal.

No segundo roteiro foram experiências vividas de modo intenso. Foi uma viagem intensa de sentimentos; que nem eu saberia dizer se algum dia conseguirei me desfazer das sensações que marcaram esses seis meses. Aceitação, desprezo, momentos sem respostas, dúvidas, diferença, indiferença. Tudo junto e muito intenso. 
Enfim, foi uma viagem ao mundo do "outro", ao mundo desconhecido, do visível ao invisível. Imagens capturadas no campo da pesquisa, que precisam de uma (re)visão minuciosa. Imagens em movimento, que precisam parar. E que, paradas, são apenas "uma imagem", um recorte de uma paisagem. Um olhar pela janela de um trem parado. Um quadro com uma moldura que esconde o restante do retrato. Um silêncio. Mas um silêncio que diz muito. (Marques, 2009: 25-251).

Metaforicamente, tal e qual um migrante, eu sabia de onde estava partindo sem saber onde chegaria. Lancei-me nessa longa travessia, acreditando mas sem dar conta de que ao viajar, ou embarcar nessa etnografia nós nos preservamos e nos transformamos, reafirmamos e nos transfiguramos, nos afinamos e desafinamos, como diria Octávio Ianni (2004: 153).

\section{Referências}

AMORIM, Marilia. O Pesquisador e seu outro: Bakhtin nas Ciências Humanas, São Paulo, Musa Editora, 2001.

BENJAMIN, Walter. "O Narrador", in: Obras escolhidas, São Paulo, Brasiliense, 1985.

CUNHA, Isabel Ferin. "A mulher brasileira na televisão portuguesa". in: Actas do III SOPCOM, VI LUSOCOM e II Ibérico, Vol. III, 21-22 de Abril, 2004.

GEERTZ, Clifford. "O Estar Alli. La antropologia y la escena de la escritura", in: $E l$ Antropologo como autor, Buenos Aires, Ed. Paidos Studio, 1989, pp.11-34.

IANNI, Octávio. "Uma longa viagem", in Tempo Social. São Paulo, vol.16, no 1, 2004.

MAGNANI, José Guilherme \& TORRES, Lilian de Lucca (orgs). Na Metrópole: textos de antropologia urbana, São Paulo, Edusp, 1996.

MARQUES, Vera Lúcia Maia. Conversão ao Islam: o olhar brasileiro, a construção de novas identidades e o retorno à tradição, São Paulo, dissertação de mestrado, Antropologia, Pontifícia Universidade Católica de São Paulo - PUC/SP, 2000, 181p.

MARQUES, Vera Lúcia Maia. Sobre práticas religiosas e culturais islâmicas no Brasil e em Portugal: notas e observações de viagem, Belo Horizonte, tese de doutorado, Sociologia, Universidade Federal de Belo Horizonte - UFMG/BH, 2009, 270p.

SIMMEL, Georg. "O estrangeiro", in MORAIS, F ${ }^{\circ}$ Evaristo (org). Simmel, São Paulo, Ática, 1983.

Recebido em: 27/03/2015

Aprovado em: 22/05/2015 